\title{
Exploring Sonic Meaning and Embodiment in Human Cultural Transmission From a Pedagogical Perspective
}

\author{
Rebecca Rinsema ${ }^{1 *}$ and Jashen Edwards ${ }^{2 *}$ \\ ${ }^{1}$ School of Music, Northern Arizona University, Flagstaff, AZ, United States, ${ }^{2}$ Don Wright Faculty of Music, Western University, \\ London, ON, Canada
}

The authors explore how sonic materials, specifically everyday sounds and songs, create and communicate personal, sociocultural, and ecological meanings. From the lulling passages of a pastoral movement streaming through a symphony hall to the rollicking screams at stadium concerts to the roaring rhetoric and social distortions of divisive political-speak, sound and music signal frequencies and frictions at play in the human

OPEN ACCESS

Edited by:

Brian Boyd,

Columbia University, United States

Reviewed by:

Paromita Pain

University of Nevada, United States Michelle Epstein Garland, University of South Carolina Upstate, United States

*Correspondence:

Rebecca Rinsema rebecca.rinsema@nau.edu Jashen Edwards jedwa4@uwo.ca

Specialty section: This article was submitted to Culture and Communication,

a section of the journal

Frontiers in Communication

Received: 23 February 2021 Accepted: 23 April 2021

Published: 20 May 2021

Citation:

Rinsema R and Edwards J (2021)

Exploring Sonic Meaning and

Embodiment in Human Cultural

Transmission From a

Pedagogical Perspective.

Front. Commun. 6:671486.

doi: $10.3389 /$ fcomm.2021.671486 experience. Literacies are cultivated, sounds embodied, and ways of sensing, knowing, and being in the world are sonically communicated and established. What happens when sounds encountered in one's everyday experience are excavated, sampled, and remixed? What new meanings may be derived? What old meanings might be challenged and reconstituted and reconstructed into new forms of knowing and being? What happens when songs or timeless tunes are analyzed and detangled from their ordinary meanings? How might listeners make the familiar strange and thus renew knowings? And what does any of this mean for the flux and firmness of human cultures in motion?

Keywords: sound studies, music, embodiment, formalism, anthropocentrism, pop-drop, music education, critical pedagogy

\section{INTRODUCTION}

Here we explore sonic meanings as they exist in everyday sounds and songs, with an emphasis on their interactions and their communicative capabilities. We view the migration of sonic materials from everyday sounds, and their experiences, to song as providing, in part, the foundation for human interpretation of music as well as providing new possibilities and agency in the interpretive process. Such new possibilities partially constitute the process of human cultural transmission through sonic materials. To begin, we trace a theoretical thread pertaining to music/song and meaning within the Western tradition. We move from traditional esthetics to hermeneutics, critical theory, phenomenology, and ecological theory of perception. We identify embodiment and environment as particularly important to constructing song meanings in a nonanthropocentric way and demonstrate such processes through an analysis of the song "Clarity," by Zedd, which constitutes Case Study 1. Next, we explore how ordinary sounds constitute social and political structures that support and limit human agency. We provide examples of how the migration of everyday sounds to musical contexts can disrupt the limitations such social and political structure enforce, thus catalyzing creative agency and critical resistance. We present two additional case studies whereby students collect, classify, critique, and create original compositions from sounds 
streaming through their everyday life. Finally, we identify agential possibility as an essential feature of human cultural transmission in the context of all things sonic.

We engage these topics not only as music and sound scholars but also as music and sound educators. As such, the case studies cohere in their connection to the classroom, and we intend them to elucidate the theoretical territory that we hypothesize and explore. $^{1}$

\section{Theoretical Thread: Song and Meaning}

Music's meanings and communicative capacity to evoke feeling/ emotion has been a point of consternation among musicologists and music theorists for some time. Eduard Hanslick's "On the Musically Beautiful," a seminal modern esthetic argument on the subject, provides the touchstone for later formalist scholars who argue that music has no meaning (Hanslick and Payzant, 1986). Hanslick argues that the "beautiful," meant broadly as "esthetic value" (Gracyk, 2007) resides not in music's relation to feeling and/or emotion but rather within the relationships of the sounds themselves. Hanslick places particular importance on melody and harmony, the foremost elements of Western classical music. Central to Hanslick's argument and the arguments of later formalists is the concept of the "musical work," theorized as an esthetic entity that exists outside of each playing/hearing of a piece. The nature of a musical work has important links to notation and composers' intentions, both of which are conceived strictly in the Western classical sense, and few links to listeners and/or musicians. Esthetic value resides in the musical work, which is defined separately from its context. As such, "context," including listeners, musicians, and the culture within which they are embedded, is of little interest to the formalist.

With formalism as the frame, one which precludes context as an important site for investigation, musicologists and theorists have for some time limited themselves to notation and idealized versions of the musical work (constructed via speculations about "composer intentions") in order to understand how music could be meaningful or have a relationship to emotions. As one can imagine, this is a rather difficult task, like mapping a home plumbing system by looking down the kitchen sink with a flashlight. Naturally, within the formalist frame, questions of human and nonhuman cultural transmission via sound, those questions engaged in this research topic, are unexplored. Even so, an exploration of formalism's connection to anthropocentrism, engaged within this research topic, is a rich one.

\section{Formalism and Anthropocentrism}

The topic at hand, with its push away from anthropocentrism, is interesting when considered in relationship to the still strong hold of formalism on the music discipline. Some might argue that formalism does not have quite the hold that it used to; we would agree. Ethnomusicology, with its roots in anthropology, has been

${ }^{1}$ Rinsema is the author of Theoretical Thread: Song and Meaning as well as Case Study \#1. Edwards is the author of Theoretical Thread: Sounds of Life as well as Case Studies \#2 and \#3. The discussion section is co-authored. (to varying degrees of success) incorporated into the music discipline, and New Musicologists take culture into account in direct rejection of formalism. Such scholars, not without struggle, are now highly regarded in the discipline. That being said, the operating principles of the National Association of the Schools of Music (NASM) which determines music curricula in colleges and universities across the United States remain largely formalist. And, the continued dominance of Western classical music in the academy rests on formalist foundations.

Formalism is distinctly modernist, and modernism is the anthropocentric era that this research topic pushes against. And yet, there is a distinctly antihuman quality to formalism, in its rejection of context and culture. On one hand, music formalists were influenced by the pull of rationalism, a trait that supposedly distinguished humans from animals. In this regard, the formalist championed and put at the center a "distinctly" human quality (we now know that nonhuman animals can also be rational, see Hurley, 2010). On the other hand, there is an intermingling of romantic ideals, and the Cartesian religiosity that came before it, along with rationality in the formalist mindset, one that ultimately demeans and devalues something as central to the human condition as culture, including, of course, cultural transmission.

Hanslick's formalist arguments should also be put in context. In the 19th century, there was a sort of culture war between reason and feeling. In music, this debate saw absolute music (music without words or representation), for example, symphonic works by Beethoven, pitted against the representational musics of, for example, Wagner and Berlioz. The question was: does the absolute or the representational have more esthetic value? For Hanslick, formalism was an important rebuttal to the strong pull, back toward affect, sentimentality and feeling, even more fully expressed pre-enlightenment. This struggle between the progressive and conservative played out across the disciplines. In music, the "reason" side of this debate could not escape the trappings of older debates and worldviews. Both sides leaned into religious (Cartesian) mind/body dualism. Where the formalist championed the reason of the mind, the representationalist championed the feeling of the body. Furthermore, esthetic value or "beauty" to use Hanslick's turn of phrase was viewed by both sides as having transcendental power. Ultimately, transcendence was a way to move beyond the human to connect with or become some higher power. In this way, both sides demonstrated god-centric rather than anthropocentric tendencies, again reflecting preenlightenment thinking. The idea is that formalism's hold on the discipline of music reflects more clearly the persistence of medieval religious worldviews than it does the anthropocentrism of modernity.

Ironically, then, one of the ways the music discipline moves toward a less "anthropocentric" (which is actually a "godcentric") account of music is in acknowledging the ways music is an expression of humanness in its fullness, not just as an expression of human rationality and reason: An acknowledgment of the bodily/"animal" qualities of being human is one antidote for the version of anthropocentrism manifested in formalism in music. 


\section{Musical Meaning and Embodiment}

Some music scholars have taken a more inclusive approach to human experience with respect to music and song analysis. As an extension of the esthetic formalist tradition, Peter Kivy theorizes that the meanings of musical contours map onto human physical contours that have emotional content. For example, a downward gaze and resulting curvature of the neck signal sadness, which maps onto downward melodic gestures, sometimes signals for sadness. But there are others as well (Kivy, 2002).

Hermeneutics and critical theory are theoretical frames that reveal the cultural forces that grant music and song their meaning. Lawrence Kramer and Susan McClary provided seminal work using these frames. Using hermeneutics, Kramer argued that music could be "read" for meaning just like any text (Kramer, 2011). Such readings have an intrinsic relationship to contexts and the interconnected positionalities of the listeners, musicians, and composers, whose definitions are only loosely tied to the Western classical tradition. Most importantly, Kramer's version of musical hermeneutics entails that readings are made by "subjects," who are endowed with all the freedom and agency that subjectivity suggests. Musical meaning, therefore, does not exclusively reside within the work. Kramer's arguments are animated by the linkages between "music and feeling, emotion, sensation, memory, and desire" (Kramer, 2011, 3). And each of these is linked to physicality; they are embodied elements of human lived experience.

Critical theory is compatible with Kramer's approach. Critical theorists in music acknowledge that sounds can be associated with groups of people, ideas, or things. These sounds can be set within contexts in ways that reinforce and/or undermine commonly held beliefs about those groups of people, ideas, or things. As such, music is politically powerful, upholding or undermining the status quo. Susan McClary's feminist readings of classical music describe how the sonata form, for example, upholds patriarchal political structures: The masculine primary key conquers the feminine secondary key (McClary, 1991, 53-79). As such, McClary engages with how music reflects cultural inequalities, inequalities that are very often built on embodied differences.

It might seem as though phenomenologists would quite obviously deal with sensorial and embodied aspects of musical meaning and experience. While this is true of contemporary phenomenologists, especially those coming after Merlau-Ponty, the early phenomenologists (Husserl, Dufrenne, Conrad, and Schutz) focused on the phenomenological object, or the music itself (often in written form), to understand the "essence" of musical experience. In this way, they fell in line with the formalists who focused on the musical work to the exclusion of cultural contexts. Listeners were understood to lack agency and creativity in the listening/interpretive process. For Husserl in particular, individual/subjective idiosyncrasies stemming from enculturation were to be "bracketed" out of phenomenological analysis (Husserl, 1964). Later, music phenomenologists (Smith, Clifton, and Bartholemew) took into account and focused on the subjective positionalities of listeners, including their idiosyncrasies. Work that follows in this phenomenological vein began in the late 1980s in music theory and gained momentum in the 2010s in the music education and musicology areas (Lewin, 1986; Pio and Varkøy, 2015; Clark and Rehding, 2016).

A direct link between embodiment and musical meaning is made by Eric Clarke via the ecological view of perception proposed by James Gibson (1986) and, later, Susan Hurley (1998) and Alva Noë, 2006. The ecological view counters the computational view of perception, which specifies that constructions of representations (primarily visual) of the external world allow for human action. The computational view dominated throughout the 20th century, and tempered versions continue to dominate into the 21 st century. In its emphasis on the visual, computational perception research centers on retinal images, neural mechanisms, and computational models required for creating such representations. The ecological view, on the other hand, foregoes representation altogether.

On the ecological view, action and perception are integral to one another. Humans are perceptually attuned to the environment for the purposes of action. For Clarke, attunement accounts for how, for example, inherent to the thud of the bass drum is an abundance of meaning, including the motion of that sound, the space within which that motion was enacted, and its directionality which has implications for the subjective positioning of the listener. Certain sounds, based on their motion, space, and directional qualities, among others, "afford," for example, fear and anxiety, or wellness, safety, and security. Such emotions and mental states inspire action. The meanings of musical sounds, thus, are intrinsically linked to our attunement to and the meanings of everyday sounds, which begin to blur the conceptual boundaries between everyday sonic material and musical sonic material. Furthermore, while certain sounds afford emotions, mental states, and actions, such things are not determined. Instead, like Kramer, the ecological view maintains the agency of the subject.

We find Clarke's account attractive in its ability to connect embodiment, the environment and sound/music meanings such that there is theoretical continuity between human and nonhuman animals in the realm of sound and song. Afterall, there is no reason to think that nonhuman animals could not be attuned to their environment in much the same way as Gibson and others suggest is true for human animals. In fact, evidence for the view relies heavily on examples of behavior of nonhuman animals (additionally, see: Krause, 1996; Rothenberg and Ulvaeus, 2001; Mithen, 2005; Krause, 2012; Rothenberg, 2019). Clarke's work can be classified as Sound Studies, an interdisciplinary area of study that focuses on the sensorium in relation to sound and meaning, including music (Sterne, 2012; Pinch and Bijsterveld, 2017; Lingold et al., 2018). Generally, scholars in this area demonstrate little interest in upholding musical genre hierarchies or the music/nonmusic hierarchy both of which reinforce anthropocentrism and are prevalent in American academic music settings. Also within the sound studies frame, Nina Eidsheim's (2015) analysis of Juliana Snapper's underwater singing brings attention to the materials that the sound and voice rely on, namely, bodies and mediums (air, water, or other substance). This work indirectly calls attention to the 
geocentrism of scholarly accounts of music, sound, and meaning, which have largely been explored with the substances and environments of earth in mind.

\section{CASE STUDY 1: "CLARITY" BY ZEDD, FT. FOXES}

Following Clarke, we posit that the migration of sonic materials from everyday sounds, and their experiences, to song and vice versa constitutes part of the foundation for how humans interpret music and enact agency in the interpretive process. At the same time, we take all of the theoretical frameworks mentioned in the previous section to be possible tools for analysis, in keeping with our view that music is a heterogeneous or "composite" (Eidsheim, 2011, 149) concept. The following case study demonstrates these interactions.

\section{The Pop-Drop Form}

The traditional popular music form "broke," some scholars contend (Sloan et al., 2020, 46-52), when the pop-drop form entered the scene in the 2010s. The pop-drop form was ushered in via EDM remixes of pop songs and refined via EDM/pop artist collaborations. One might argue that the form's solidification came when pop artists started utilizing the form independent of EDM collabs. 2016 has been called the year of the pop-drop as about $20 \%$ of the billboard hot 100 songs had pop-drops (Harding, 2016). This is note-worthy and exciting for popular music scholars because of how long the traditional "Verse, Chorus, Verse, Chorus, Bridge, Chorus" pop form has dominated-over half a century. While precursors and permutations of the traditional form have been prevalent throughout these same decades, the vast majority of them retain the importance of the chorus as the moment of arrival-that is, the part that melodically and lyrically sticks in your head. But with the pop-drop form, the chorus serves primarily as a build-up toward an instrumental, bass driven section-the part that rhythmically sticks in your body (at least in the listening moment).

The terms "tension" and "release" are often used within the Western classical music theory to describe how the harmonies in the traditional form operate in each section of the song (such terms were originally reserved for classical music; application of them to popular music began in the mid-20th century). But, with the pop-drop form, "tension" is often not created harmonically, but rather rhythmically. The theoretical language utilized to delineate these structural moments acknowledges the embodied nature of them; tension and release are physical and embodied. But, the embodied nature of the pop-drop is generally not at the forefront of discussions of this form. Here we aim to provide a fuller account of how embodiment plays out in the popdrop form using a particular instantiation of it, "Clarity" by Zedd, featuring Foxes. Furthermore, we explore the song's links to everyday spaces and sounds and agential possibilities in relationship to its ecological affordances. Finally, we explore how certain actions in the temporal moments of listening can be received and interpreted as forms of resistance.

\section{Embodiment in "Clarity's" Drops}

There are four bass drops in "Clarity." The first and the third afford a liberation of energy and movement, while the second and fourth afford a continuation of the energy and movement of the first and third drops. The difference in their affordances is determined by what sonic elements lead to each of these drops. These leading sonic elements are, together, known as "the build toward the drop." We will describe how the build toward the first drop affords a release of physical movement. We will also describe how the build to the third drop plays with listener expectations, providing an increased sense of liberation when compared to the first drop. The third drop, thus, affords the highest burst of physical energy from the listener.

The song includes two drop cycles as follows:

Short intro

Cycle 1: first verse, pre-chorus, chorus and simultaneous build, instrumental drop (1), instrumental/vocal drop (2)

Cycle 2: second verse, pre-chorus, chorus and simultaneous build, interlude, instrumental drop (3), instrumental/vocal drop (4).

Short outtro

The sonic elements leading to the first instrumental drop are typical of bass drops in the pop-drop form; it includes a gradual increase of texture, pitch, and rhythmic division. The increase of these three musical elements builds within the listener's body a pressure of physical energy that is released when the bass finally drops. In "Clarity," the build is as follows.

The verses begin with a single voice, syncopated supporting electronic keyboard chords, and muted electronic keyboard pulses on the eighths. Manipulated vocal echoes at the ends of the lyrical phrases imply varied types of reverberant spaces; the eighth note pulses come to the fore, providing forward momentum between vocal phrases. At $25 \mathrm{~s}$, an electronic, crisp, clean high-hat sound begins marking the main beats-the first main player in the build. At $40 \mathrm{~s}$, a timbrally rich wave moves toward the listener and crashes on the beat with a bright thud signaling the beginning of the pre-chorus. The melody of the pre-chorus is set higher than the melody of the verses. Foxes sings in her upper chest voice with a straight tone; this registration and style entails increased physical pressure on the whole of the vocal cord compared to the registration and style of the verses. At $47 \mathrm{~s}$, the texture thickens: a counter melody rich in timbre, men's voices singing in unison through tube-like resonant space. At $55 \mathrm{~s}$, the chorus begins, the straight tone singing now in the far reaches of the chest voice further increases the vocal cord pressure. At the same time, the eighth note electronic pulses further divide into sixteenths. During the second phrase and final phrase of the chorus, those pulses come to the foreground, further dividing into $32 \mathrm{nds}$, while an upward slide sound is heard increasing in pitch. This sliding sound, characteristic of the final moments of the build, is made in the physical world by pressing air out of a tube, like a slide whistle. Pressure, pitch, and rhythmic division are at a breaking point. Listeners' bodies are ready to explode with energy. And they do, with the bass finally dropping, and landing on the main beats the 
male voiced counter-melody comes to the fore, becoming the primary melody, and a new contrasting counter-melody emerges composed of ultra-electronic, thin-timbred beeps. This drop section is completely instrumental, the build and release of physical energy affords dance/movement, which is at the center of the drop experience.

The build to the third drop is the most climactic, though. While much of this build is similar to the first, there is one key difference that further builds the pressure. Between the second chorus and the third drop, there is an interlude, which is texturally thin (a sort of return to the thin texture of the verses), but thick in timbre. During this section, the initial unison, male-voiced counter-melody $(5,2,3,7,1)$ repeats in solo fashion. This section delays the drop, according to listeners' physical expectations. With each moment of delay, the pressure that was established in the previous section continues to increase, even though the texture, pitch, and rhythmic division have all been reduced sonically, their trajectories continue in the bodies of listeners. As such, this additional section allows this third drop to afford an even greater release of physical energy than the first.

\section{The Pop-Drop as Play}

Generally, the pop-drop, along with many other musical phenomena, can be viewed as a form of play. The pop-drop plays with everyday physical, bodily experiences and sensations that exist because of the specific materials human animals have evolved to exist with and the physical laws that bind them together. The pop-drop is a play on riding on a rollercoaster, among other things: the ratcheting up that is accompanied by the higher and higher pitches produced by the machinery, followed by the sort of weightless transition at the top, where the coaster car shifts from motion up to motion down, and the descent (an actual drop) and release of that potential energy, that crescendoed in the body during the whole climb. The increase in pitch and the increased rhythmic divisions within the music link to the actual increase of pitch that occurs and the increased rhythmic divisions link to the potential energy. Another example, might be the tea kettle, where molecule speed is linked (eventually) to a highpitched wail.

The rollercoaster experience is felt within our bodies, but it is the result of external forces acting upon our bodies. Eric Clarke explores how sonic relationships afford a feeling of being either inside or outside of the musical space, essentially an affordance of subject positionality. Along a similar vein, I want to mention how the pop-drop plays with forces and processes that are part of our bodies. For example, the way an air bubble feels as it makes its way from the upper digestive tract, to the esophagus, and bursts its way through the vocal cords to create a loud rumble. The increase of pressure can be likened to the increase in pitch and rhythmic division within the buildup and low rumble (burp) to the bass. The buildup of pressure and expectation, followed by an energy release occurs the same way in an orgasm. A delay of the energy release often increases it. This is the function of the additional section located just after verse two functions; it delays the third drop so as to increase the energy release of it.

\section{"Clarity's" Everyday Sounds and Their Musical Meanings}

A number of everyday sounds, or stylized versions of them, are heard within "Clarity." We will focus on a pair of sounds that is heard three times, each time at an important structural moment. The pair of sounds includes a medium- to high-pitched click followed by a fizz that disperses over five beats. These sounds are heard as each verse begins (there are two verses) and at the close of the song. In what follows, we explore how these sounds relate to these structural moments and other sonic elements to create musical meanings.

The song begins with a very curious five seconds that contain sounds associated with the following traditional instruments: strings, keyboard, and horns. The strings slide from the second to the first-scale degree to establish tonality. Next, sustained notes of the keyboard arpeggiate the first, fifth, and seventh scale degrees further solidifying that tonality. Finally, the horns move from one to five and sustain on six. The click and the fizz interrupt that resolution. Block keyboard chords replace the arpeggios in support of the melody of the verse. Gone are the strings and the horns. They will not return.

On a second or third hearing of the song, these first five seconds indicate an alternative musical space that the listener quickly departs. But the pair of everyday sounds, allows for that departure to be heard, though less decisively so, even on the first hearing. The smooth repetitive arpeggios of the keyboard that land right on the beats, grouped in threes, along with the smooth slide of the violins, and the stable tone of the horns create that alternative musical space and afford a dream-like mental state. The click and the fizz entails a departure from that musical space and that mental state, one focused with angular syncopations, lyrics, a singular melody, and, eventually, consistent tapping of crisp high-hat type electronic sounds. As such, this second musical space has evident connections to the title of the song, "Clarity."

Additionally, the click and the fizz sounds themselves reinforce a sentiment of clarity via their connection to everyday sounds and experiences. The click, together with the fizz, calls to mind the opening of a can of soda and pouring it into a glass which results in a release of the carbonation and a similar fizzing sound that dissipates over a few seconds. Drinking carbonated fluids, like soda or sparkling water, appeals to many people because of the refreshing, cleansing sensations felt in the mouth and throat. Just like carbonated drinks provide a sort of physical and mental refresh, the click and fizz sounds provide a musical refresh. And, such physical and musical meanings become entangled during the listening experience.

The second and third instances of the click and fizz occur at structural moments of the song. The second occurs just after the first and second drop sequence. It is the moment when the texture suddenly transitions from thick to thin, setting up the second verse. Thus, the second click and fizz serves as a reset to begin the cycle over again: verse, pre-chorus, chorus (including build and extra built), drop, and drop again. The third, final hearing of the click and fizz comes right at the end of the song, signaling that 
there will be no return to the dream-like musical space, heard during the song's 5-s introduction. Read with the lyrics in mind, this indicates a lack of return from the (simultaneous) chaos and clarity, characteristic of the romantic relationship at issue.

\section{Agency and Resistance: To Move or Not to Move to "Clarity"}

While the sonic elements of pop-drops afford physical movement in the form of tapping, nodding, or dancing, among other types of movements, such affordances do not determine human behavior. Humans, of course, have agency and can choose to move or not. But, the choice to move or not to move can signify a variety of messages, depending on the social context.

I regularly play "Clarity" for large groups of students in a classroom context. Movement associated with dancing is not typically associated with the classroom (especially this one, which crams the students in like sardines, shoulder to shoulder). When listening as a class, the affordance of movement is so strong, that many of the students nod their heads to the beat, and choose an even more dramatic gesture for each drop moment. Those who choose not to move are not necessarily viewed as signaling something important, as the classroom is normally a "nondancing" zone. But, imagine you are in a club or at an EDM festival in the middle of the crowd. The social expectation in this context is to be "moved" by the musical affordances. If you choose to stand still in the middle of the crowd with no physical movement or reaction to the bass drops, this would be noticed by members of the crowd, and some might interpret this behavior as a form of resistance, to both the social expectations and the music. The phenomenon I am describing here can be summed up by a Facebook users' political party affiliation (back when Facebook encouraged such bio information). It read: "My political party is the one that stands against the wall with arms folded at a dance party."

This example highlights the agency that listeners have in choosing their responses to the affordances of song, which in some contexts can be viewed as resistance. But this kind of agential action requires maintenance and effort. The following several sections highlight how listeners may not always take up that agency in relationship to the sounds of the everyday sonic world, which lays the groundwork for relational misuses and improprieties, among and between human animals, nonhuman animals, and their environments. The following sections respond to those phenomena, providing the pedagogical means to inspire human agency in the mitigation of such relational incongruencies.

\section{Theoretical Thread: Sounds of Life}

Just as music and song afford certain embodied actions that result in sent and received social-political messages, so do those sounds of our lives not typically labeled "music" or "song." Examination of such sounds provides an opportunity to better comprehend our relationship with ourselves, others, and the biotic and abiotic ecosystem with which we are inextricably interconnected. This is because, sounds are filamentary vibrating strands (re)connecting us to memories, places, spaces, events, and people, and even to other senses; sustaining moments of resonance, sometimes beneficial, other times dangerous (Berardi, 2015, 317; James, 2019). In this sense, sound signifies a "social formation constituted by struggle and struggled over" (Kheshti, 2015, xx) wherein some voices are heard, others restrained, and still others silenced within the hegemonic commotion all too common in vexed relations between power differentials (Akiyama, 2010; Rice, 2010; Siisiäinen, 2013; Gautier, 2014; Daughtry, 2015; Rice, 2016; Stoever, 2016). Sounds are fundamentally "public objects of auditory perception" (O'Callaghan 2017, 9) and are encountered and experienced in spaces Bruce Odland and Sam Auinger call, "Sonic Commons. . . any space where many people share an acoustic environment and can hear the result of each others activities, both intentional and unintentional...The sonic commons is full of asymmetry" (Odland and Auinger, 2009, 64-65).

It is in such asymmetries-personal, cultural, and sociopolitical-wherein notions of agency and resistance may be further amplified, not only within the field of music education, but education at large, particularly for pedagogies guided by principles of socially just, critical, and culturally relevant practices. As noted above, Rinsema's approach to listening within music teaching and learning spaces runs counter to the "premolded worlds" and "traditional" formalist ways music education has transmitted its musical knowledge via ideals and codes of esthetics, or as Estelle Jorgensen calls, "bodies of musical wisdom that are valued and preserved" (Jorgensen, 1997, 25). Within such "institutionalized and canonized" (Ibid.) conservations (i.e., conservatory models of music learning and teaching), "spheres of musical validity" (Ibid., 40) form a modus operandi of what it means to be musical-and who gets access to creative musical experiences. By situating "music listening as a creative activity [and] hermeneutic exploration" (Rinsema, 2017, 6 and 139-140 italics added), Rinsema sets the stage whereby we can further develop and explore analytical and interpretive methods that center students' lived sonic experiences by inviting them to listen, critique, and create musical sound pieces (SPs) out of everyday sounds. In addition to evolving an Oliverosian practice of "deep listening" (Oliveros 2005) to the world, we may also sharpen skills of what Salomé Voegelin calls, "sonic sensibility" (Voegelin 2014). For Voegelin, sonic sensibility is a dynamic listening beyond the

effort of hearing. Listening as a sensibility, as a susceptibility toward the world and the things...is not only a physiological act but an aesthetic and perceptual attitude that influences how we understand the world, its reality, knowledge, and truth...(and) reinvigorates ideas about reality, actuality, possibility, and truth...exploring sonic timespace places as sonic environments, which we inhabit as phenomenological subjects, listening intersubjectively and reciprocally: generating ourselves and the world we hear through our being in the world (Voegelin, 2014, 2-3 and 178).

In this section, we delineate a framework designed by one of the co-authors who encourages such sensibility by asking music 


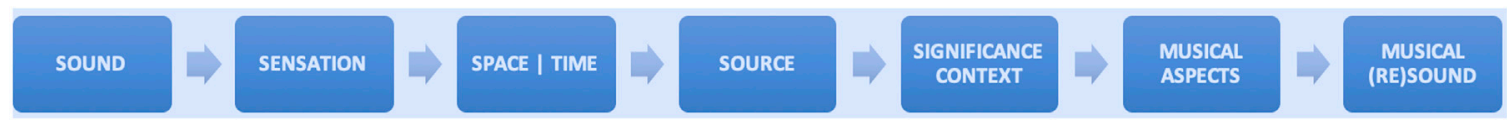

FIGURE 1 | Sound collection and classification (SCC) table.

students to tune-in, listen, reflect, critique, play, and (re)sound their Sonic Commons (see Figure 1).

These spaces may be at home, school, park, playground, job site, street, or cyberspace; really anywhere people may find themselves on their daily trek through life. Students digitally record sounds they find interesting or that "speak" to them. Then they describe their initial sensation(s), location, and any significance selected sounds may have. As students are asked to capture sounds digitally (i.e., MP3, WAV, and WMA) on their phones or audio recording devices, they are able to import them into any DAW (Digital Audio Workstation) (e.g., GarageBand, Logic Pro, Soundtrap, and Bandlab). This allows students a multitrack space to collaboratively assemble, improvise and create original compositions using sonic material they have collected. The methods of this process are meant to elucidate the multiple ways sounds can create, conjure, complicate, sustain, and rejuvenate meanings in and from students' lived experiences. It is through this sonic lifeworld method where students may uncover similar and different "meanings that can be constructed from the combining of objects of nature and objects of consciousness" (Hourigan and Edgar, 2014, 150). Objects of nature are the sounds of life encountered, experienced, excavated, and entertained. Objects of consciousness include the creative critical reflections and artifacts students create en route to exploring and (re) examining new and other meanings. These dialogical encounters open an acoustic space for students and their teachers to creatively and critically (re)engage sounds resounding in their lives.

We situate agency and resistance as central components of critical and socially just pedagogies wherein a cycle of "dialogue, reflection, and action" (Freire, 1970, 100) are vital for catalyzing creative critical consciousness. Actively listening for societal dissonances-sounds out of sync with democratic and egalitarian ideals, sounds heard from those distraught, dismissed, and disenfranchised by unjust policies or social-political prejudices, and soundbytes of hate, fear, derision, and divisiveness-is one aim of sonic lifeworld methods. Another aim is to heighten sensory awareness about the "resonant or responsive relationships" (Rosa, 2020, 145 italics original), we must create and sustain in order to transmit a new cultural paradigm built on empathy, trust, and mutual respect for all vibrating sentient beings. It is through creative critical consciousness, we contend, where humans may sense the world, not as a competitive "resource" to be picked at and peddled for profit of which our current geological age is guilty, and instead find resonance with the world in ways that open possibilities for personal and social transformation toward humane ends.
Sound can be a conduit for exploring creative critical consciousness because as Roshanak Kheshti reminds us, "Sound's form is a hermeneutical tool; a wavy and reverberant materiality, it reflects, is productive of, and also engenders through resonance" (Kheshti, 2015, 111). The two examples below offer a glimpse of how I have used sonic lifeworld methods in educational settings, specifically in high school and university schools of music. What is telling from the outset is how foreign it seems to most music students that they are entering not through music notes, or scales, or chords, but through sound itself. This speaks volumes to the "success" music enculturation has had in music education. It is not without significant consequences, however, as musical identities are also shaped by such enculturation processes in that demarcations are drawn that often delimit one's capacity to imagine themselves outside of the "institutionalized and canonized. . . product as well as process" (Jorgensen, 1997, 25; Edwards, 2021; Schmidt and Edwards, 2022). In other words, most of the students I have worked with using sonic lifeworld methods do not consider themselves improvisers or composers, as they have had no "formal" training. So by asking them to expand their creative consciousness is often a new request. By entering first through sound, however, students challenge their musical thinking as they navigate toward meaning making via sonic thinking. This is because sonic thinking "begins not from music as a set of cultural objects but from the deeper experience of sound as flux, event, and effect...(and) present us with an ontology that unsettles our ordinary conception of things" (Cox, 2017, 100 italics original). It is the "ordinary conception of things" we challenge in this article because so-called ordinary understandings of our universe, particularly as these have been constructed upon the Western value of dominance over nature, has placed humans in a perilous position that must be maneuvered away from if we are to create equitable and sustainable living conditions on our planet. Indeed, as Christopher Small observed, Western; "civilization" is "increasingly, schizoid" in its attempts to "command nature" and "disembodies" us from the natural world; lost, disoriented, and alienated from self, other, and the world (Small, 1977, 69-70). We situate listening to the sounds of life as a significant step in reorienting toward an intersubjective "resonant and responsive" (Rosa, 2020) relationship with the world "sensuously" (Abram, 1996).

\section{Sonic Lifeworld Method in Practice}

As delineated in Figure 1, sonic lifeworld methods include a Sound Collection and Classification (SCC) table. This is an online collaborative space for students to upload their sounds and complete seven data points: (1) sound, (2) sensation, (3) space | time, (4) source, (5) significance | context, (6) musical aspects, 
and (7) musical (re)sound. These data drive the creative critical aspects of engagement. In addition to the SCC table, as will be elucidated in the following examples, a Sound Walk (SW), and an original SP are also a part of sonic lifeworld methods. Altogether, sonic lifeworld methods are comprised of seven elements; however, the three aforementioned are highlighted in the examples below. In the university music student example, I will turn attention to patterns noticed wherein sonic sensibility and creative agency were observed. In the high school case study, I will show how sonic lifeworld methods can open a space for creative critical voice wherein agency and resistance prevail.

\section{CASE STUDY 2: UNIVERSITY SETTING-SONIC THINKING, SONIC SENSIBILITY, AND CREATIVE AGENCY}

University music students are rarely prompted to listen for, locate, or analyze sounds outside of the accustomed tempered scale system (i.e., do, re, mi, and diatonic/chromatic). So, their first challenge is to think and listen outside of tonal music's theoretical concepts (i.e., scale degree, chord progressions, and common period four-part harmonic "proper" resolution). Most seem pleasantly surprised that sounds they had never considered, sounds "heard" and bypassed everyday, could contain meaning. Two days before our 90-min Sound Session Workshop, students were asked to record five to seven sounds they found interesting. Students shared their sounds and the significance and meanings sounds held before embarking on a group improvisation/collaborative composition project using selected sounds from the SCC table. Some students were surprised to hear how others in the class reinterpreted their sound either vocally or with a musical instrument. They also noted how sounds held different meanings for different people, thus recognizing sound's personal and context-dependent nature. For example, one student stated that the "ticking" kitchen clock brought her back to the "big clock in (her) grandmother's room." She recalled nostalgic visits as a child where she was "happy" hearing stories about how the big clock was a wedding gift and that her "grandfather saved his money from sharecropping to build a special table for the clock to sit on." For her, the ticking with its "steady, rhythmic pulse; short and precise (and) varying pitches" had a "calming" effect. However, another student's "old clock" sound caused them to feel a sense of "anticipation" which interfered with their "trying to relax after a stressful day."

Students also described how a sound could have multiple meanings even for them, thus demonstrating sound's complexity and capability to conjure varied emotional states of being. For example, one person said they felt "annoyed" at the sound of a "train whistle." However, it also "reminded (them) of home." They elaborated:

When I was a child my friends and I used to explore my town (where trains are moving through 24/7). Whenever we'd get lost we'd use the sounds of the trains to find our way back home. As I aged, the sound became incredibly annoying as it was just an inconvenience rather than a childhood tool; either way, it makes me very nostalgic.

One student captured the sound of their "sniffling" and said, "I am radically aware of my own health. I can feel the mechanism of my own breathing and trying hard not to sniffle." One other recalled feeling "scared" when she heard the sound of "the power going out" in her house. She said,

I was lying half awake in my bed when the lights flickered out and my fridge stopped humming. The power had went out and I could hear and feel all the energy drain out of the building. It was like in movies when an apocalypse causes all electrical currents on earth to cease.

Feelings of surprise, elation, fear, worry, amusement, satisfaction, intimidation, relief, and a host of other emotions were attributed to sounds students collected. This left much room for critical discussion and debate, as well as a variety of affective "moods" to choose from to color the final SP compositions.

Students tuned-in sonics at play in nature, or as one student put it, "the bush" (e.g., birds, dogs, wind, and rain) events and spaces they had encountered regularly en route to campus, yet had not really "paid that much attention to." Such (re)connection with the environment allowed opportunities for students to recognize their intersubjectivity with local ecologies. Thus, sound reoriented them toward empathetic engagement with their surroundings so they could hear and listen anew. One student said, "I was tired and stressed, but hearing the birds I realized that other things were awake and doing well, and that made me feel better." To the "purring" of her kittens, another student said, "My two kittens trust me enough to fall asleep on my chest and stay through the night, they were rescued from abusive owners so that trust is an incredible gift."

Students practiced honing their sonic sensibility and also discovered imaginative and creative ways to (re)sound their sonic material musically, thus stepping into new and unfamiliar roles as improvisers and composers thereby (re)negotiating their musical identities as creative agents. For example, the sound of water trickling from a nearby lake into a students' room before bedtime was (re)sounded by a "deep drone timbre" played by French horn, a "steady pulse" provided by a "low drum" and a "gentle" steadily growing "trill" played by a clarinet mid-register. An approaching food truck behind a students' dorm room that at first sounded "rumbly and ghostly terrifying" and then "piercing and beepy with steady pulsations" was reimagined into growling brass and woodwinds softly buzzing and humming through their instruments, steadily shape shifting sounds, reminiscent of Reichian "phasing" techniques as students performed in different parts of the classroom, sometimes antiphonally to conjure the element of spatial aural surprise. Sounds of train whistles, computer keyboard, video games, electric heaters, alarm clocks, and coffee machines, were all recontextualized compositionally. This is not without insignificance, given the ways musical identities are typically shaped, formalized, and 
"consecrated" via the "aristocracy of culture" (Bourdieu, 1984) within university and schools of music (Wright, 2010; Burnard et al., 2015). Indeed, as Cox asserts

Our ordinary relationship to music is one of unthinking familiarity-the apprehension and production of perceptual and affective clichés, ready-made forms, conventions, and cultural associations that prevent us from hearing it as anything else. In short, for the most part, music operates for us according to the model of recognition and does not provoke us to think or to ask "what is this sound?" and "what are its conditions of existence?" (Cox, 2018, 137)

After the workshop, some students corresponded with me and said they had noticed how they were even listening more closely to the sound they produced on their instruments and voice during studio practice and ensemble rehearsals and performances, thus renewing their relationship with music on their terms.

\section{CASE STUDY 3: HIGH SCHOOL SETTING-SONIC THINKING, SONIC SENSIBILITY, CREATIVE AGENCY, AND CRITICAL RESISTANCE}

Amidst the 2016-2017 presidential campaign, the Sonic Commons within the United States was immersed in divisive Trump-speak and pervasive "jingoistic forms of patriotism" (Giroux, 2010). Xenophobic threats to build a wall between Mexico and the United States did not go unnoticed or unfelt by high school music students I was working with in Chicago's South Side. Some students had family members in Mexico and were audibly and visibly upset. To open a creative critical space for students to express their voices, we embarked on a soundpiece composition project. Taking inspiration from Pink Floyd's concept album, The Wall, students interrogated their own definitions and conceptions of walls, critically engaged in debates about democracy, racism, and exclusion, and examined music's sociopolitical role in addressing injustice. Utilizing Russoloian methods of instrumentation (i.e., Arte Dei Rumori/The Art of Noise, 1913), students made a list of the raw materials that go into constructing a wall (e.g., cement, gravel, wood, water, hammer, and nails) and then collected and classified sounds according to their orchestrative potential. Students also chose to digitally capture a sound bite of Trump speaking at a Republican rally where senate-elected sycophants and Trump loyalists soaked in and eerily echoed, "We're going to build a wall!" and used this clip to interject their own esthetic response. Then they imported sounds into Soundtrap (a collaborative online DAW) and improvised, composed, and produced three tableaux delineating the construction, deficits, and crumbling of walls. For 6 weeks, students worked collaboratively developing their aural, improvisation, and performance skills while composing an original sonically stimulating piece.
The Wall Project draws upon the power of the remix. Remixing, as Korina Jocson reminds us, is "to appropriate, borrow, and blend texts to create new(er) texts... The technique in remix provides ease in sharing and invites a community to participate. . Remix...is not simply about a change in content (a derivative) but also a change in context (a different meaning)" (Jocson 2018, 50). Encouraging students to actively sample sounds they encounter in the Sonic Commons opens opportunities for them to re-engage unsound rhetoric and sociopolitical noise streaming across media channels and compose a response. Student voice is integral to sonic lifeworld methods because "The first and fundamental organ through which we enter into a responsive relationship with the world and make the world respond to us. . .is the voice" (Rosa, 2020, 63 Italics original). Raw sounds and voices were the material with which students identified inconsistencies, puzzled explanations, renegotiated meaning, and revolted counter-narratives charged by the force of their own voices, their own "storytelling" (Lewis, 2020, 73). Sonic lifeworld methods in this sense provides a dialogical acoustic space for students to play, explore, excavate, and examine Sonic Commons, en route to naming frictions and tensions heard, as they resample, remix, rehearse, and resound alternative knowings. The work required "to know alternatives" is central to critical and transformative pedagogies, for ultimately such pedagogies are about enacting the "dialectic of freedom" by embracing our relationship with the world in an effort to "unconceal...to create clearings, spaces in the midst of things where decisions can be made" (Greene, 1988, 5, 58). Thus, it is through an "ethos of experimentation that is oriented toward carving out spaces for resistance and reconstruction" (Coté et al., 2007, 317 and 328), where students may sharpen their skills of sonic sensibility and claim their stake in the sociopolitical sphere. Such reclamation is a powerful pedagogical tool when working toward nurturing creative agency and critical resistance.

By simply asking students to listen deeply and sensibly to their world they may "record their own personalized, specified, modeled meanings, affirmed in time with the beat-a collective memory of order and genealogies, the repository of the word and the social score [that] reflects a fluid reality" (Attali, 1985, 9). When considering knowledge, transmission, and embodiment in Attalian terms, then, what Robin James calls "acoustic resonance" becomes something we can apply toward the development of creative agency and critical resistance. For James, acoustic resonance is a "specific type of vibratory movement: rhythmically oscillating patterns of intensity. . These patterns interact in rational or irrational phase relationships. Resonance thus describes either the consonant, rational interaction of phase patterns or the dissonant, irrational interaction of such patterns" (James, 2019, 63). In order to disrupt oppressive epistemologies sounding in the Sonic Commons, it is essential to tune-in and keep the ears open so as to detect irrational signal phases that perpetuate social injustices. 


\section{DISCUSSION}

\section{The Migration of Everyday Sounds and Musical Sounds in the Creation of Meaning}

Above we posited that the migration of sonic materials from everyday sounds, and their experiences, to song constitutes part of the foundation for how humans interpret music and sound. We demonstrated those migrations within the three case studies. With Case Study 1, we showed how everyday sounds and experiences can be extrapolated and "played" upon within song. The reconfiguration and re-emphasizing of those everyday sounds and experiences in structured esthetic contexts allow listeners to reorient themselves to their physicalities. Song creators and listeners express their agency in this reorienting process, which is itself a meaning-making process. In Case Studies 2 and 3, we demonstrated how teachers and students can reorient themselves toward everyday sounds in their migration from the sonic landscape to an intentional pedagogical landscape-one that values creativity, criticality, and collaboration. Students express agency in this reorienting process, laying the groundwork for further agential and meaningful processes of resistance and reconstruction, not only of sociopolitical externalities but also of deeply personal internal processes of often conflicting creative ways of being musical.

\section{The Shift From Anthropocentrism}

In the first theoretical thread, we argued that a shift away from anthropocentrism within music studies includes a shift toward embodied approaches to understanding musical meaning. We provided an example of how musical meaning can be interpreted using such approaches in Case Study 1. There we used the ecological view of perception and Clarke's application of that view to music and sound, in order to come to an embodied understanding of the bass drop in EDM and recent pop songs. In Case Studies 2 and 3, we drew upon Voegelin's notion of sonic sensibility, which informed the SCC table and Rosa's theory of "resonance" providing students an opportunity to explore their embodiments in relationship to everyday sound and the sensory experiences of those sounds. The manipulation of those sounds into an esthetic frame designed by the students provided opportunities for them to realize the fluid relationship between everyday sounds and what humans have to this point called music. This fluid migration between the everyday and the esthetic highlights the inherent relation between humans and the environment, while also providing a possible window into how nonhuman animals might engage with the esthetic. We are reminded here of Bernie Kraus' important works Notes from the Wild (1996) and The Great Animal Orchestra: Finding the Origins of Music in the World's Wild Places (2012), both of which alert us to the role and significance sound making and meaning play in worlds other than human. These potentially similar environmental relations had by human animals and nonhuman animals along esthetic lines have been hidden from view by anthropocentric theories of music and meaning dominant in the 19th and 20th centuries.

\section{Cultural Transmission From a Pedagogical Standpoint}

Educators hold a unique and significant responsibility to develop knowledge within students. Such knowledge is embedded within knowledge systems and systems of meaning making. Educators, thus, have a further important role in either maintaining/reifying established knowledge systems or dismantling the established knowledge systems as a process toward rebuilding the new. We fall in line with Jorgensen in this regard, who identifies the educator's responsibility

...to redress society's evils and act as agents in its transformation and regeneration. Simply transmitting values from the past without questioning their veracity, relevance, practicality, or vision is failing to do the work of an educator in the fullest sense of the word. As such, it is, by default, oppressive and miseducative (Jorgensen, 1997, 78).

We respond to this responsibility by putting students own musical knowings and creations at the center of our work and enacting Rubén Gaztambide-Fernández's "cultural production":

...the active engagement in reorganizing the symbolic content of our social being-that oppressive boundaries can be challenged in the search for social justice. This in between process requires the inner engagement with direct experience and the production of new outer representations. (Gaztambide-Fernández, 2007, 36 italics original)

In Case Study 2, we can see how students used sonic material from their everyday inner representations of their experiences of life as a catalyst to think through and create new and other outer representations. This active engagement with real and symbolic content of their sonic social being opened opportunities for them to produce their own cultural (and esthetic) "rules" for creative engagement. While students in this case study were not necessarily addressing large societal ills, they were in a very real sense redressing music education's sometimes strict hold on their musical identities by recognizing themselves as composers. In Case Study 3, students directly challenged "oppressive boundaries" through the enactment of cultural production, and in their search for social justice they reclaimed their creative critical rights by voicing their dissent against a literal wall. Thus, students (and myself as facilitator) discovered the "in between processes" of moving our inner disdain, and for some real fear, into a new outer product representative of hope and a commitment to the raising of social consciousness.

Since the rise of industrialism and on into our current corporatized and technologicalized real and virtual worlds, the dominant means of cultural reproduction have proven detrimental, particularly in the West. Scholars identify "predatory capitalism" (Giroux, 2015, xx), “competition and acceleration" (Rosa, 2020, 5, 21-22), and the 
cooptation of "creativity and the imagination" (Haiven, 2014) as having influenced and infected our relationship with self, other, and the world. We are in an ecological crisis externally and internally as our orientation with/to the world is too often shaped by a view that sees success in life (and in education) as an accumulation of resources to be had, not necessarily sensually or empathetically experienced (Rosa, 2020, 27, 145). Such attitudes have flung our ecology into a spiral of uncertainty as made clear by global warming, the fragile state of our oceans and wildlife and our current social-political crisis and rising fascism. Recognizing the fragility of life and its relation to current sociopolitical and economic structures is imperative. Pedagogies of sound can not only provide fertile ground for that recognition to take root but also address

\section{REFERENCES}

Abram, D. (1996). The Spell of the Sensuous: Perception and Language in a MoreThan-Human World. New York: NY: Vintage Books.

Akiyama, M. (2010). Silent Alarm: The Mosquito Youth Deterrent and the Politics of Frequency. Can. J. Commun. 35, 455-471. doi:10.22230/cjc.2010v35n3a2261

Attali, J. (1985). Noise - the Political Economy of Music. Minneapolis: University of Minnesota Press.

Berardi, F. (2015). And - Phenomenology of the End Sensibility and Connective Mutation. South Pasadena, CA: Semiotexte(E). doi:10.2495/safe150081

Bourdieu, P. (1984). Distinction - A Social Critique of the Judgment of Taste. London: Routledge.

Clark, S., and Rehding, A. (2016). Music in Time. Phenomenology, Perception, Performance. Cambridge, MA: Harvard University Press.

Coté, M., Day, R., and de Peuter, G. (2007). Utopian Pedagogy: Creating Radical Alternatives in the Neoliberal Age1. Rev. Educ. Pedagogy, Cult. Stud. 29, 317-336. doi:10.1080/10714410701291129

Cox, C. (2018). Sonic Flux - Sound, Art, and Metaphysics. Chicago and London: The University of Chicago Press. doi:10.7208/chicago/9780226543208.001. 0001

Cox, C. (2017). "Sonic Thought," in Sonic Thinking: A Media Philosophical Approach. Editor B. Herzogenrath (New York, NY: Bloomsbury Academic), 99-109.

Daughtry, J. (2015). Listening to War Sound, Music, Trauma, and Survival in Wartime Iraq. New York: Oxford University Press. doi:10.1093/acprof:oso/ 9780199361496.001.0001

Edwards, J. (2021). "Improvisational Encounters with the Sonic Lifeworld," in The Improviser's Classroom: Pedagogies of Adaptive Performance, Social Engagement, and Creative Practice. Editors D. Fischlin and M. Lamanno.

Eidsheim, N. S. (2015). Sensing Sound: Singing \& Listening as Vibrational Practice. Durham, NC: Duke University Press. doi:10.1215/9780822374695

Eidsheim, N. S. (2011). Sensing Voice. Senses Soc. 6, 133-155. doi:10.2752/ $174589311 \times 12961584845729$

Freire, P. (1970). Pedagogy of the Oppressed (Myra Bergman Ramos, Tr.). New York, NY: Continuum.

Gautier, A. (2014). Aurality - Listening and Knowledge in Nineteenth-Century Colombia. Durham \& London: Duke University Press.

Gaztambide-Fernández, R. (2007). Inner, Outer, and In-Between: Why Popular and Matter Arts Matter for Inner City Youth. Orbit 36 (3), 35-37.

Gibson, J. J. (1986). The Ecological Approach to Visual Perception. Hillsdale, New Jersey: Lawrence Erlbaum Associates, Publishers.

Giroux, H. (2015). Education and the Crisis of Public Values: Challenging the Assault on Teachers, Students, and Public Education. New York: Peter Lang Publishing.

Giroux, H. (2010). Patriotism and the Culture of Fear: Beyond the Discourse of Moral Absolutes. Available at: https://politicsandculture.org/2010/08/10/ patriotism-and-the-culture-of-fear-henry-giroux-2/ (Accessed August 10, 2010). doi:10.1061/41141(390)20 cultural transmission and embodiment with both words and action.

\section{DATA AVAILABILITY STATEMENT}

The raw data supporting the conclusion of this article will be made available by the authors, without undue reservation.

\section{AUTHOR CONTRIBUTIONS}

All authors listed have made a substantial, direct, and intellectual contribution to the work and approved it for publication.

Gracyk, T. (2007). Outline of Hanslick. Available at: http://web.mnstate.edu/ gracyk/courses/aesthetics\%20of\%20music/hanslick_outline.htm (Accessed July 2, 2007). doi:10.3998/mpub.155334

Greene, M. (1988). The Dialectic of Freedom. New York and London: Teachers College Press.

Haiven, M. (2014). Crisis of Imagination, Crisis of Power: Capitalism, Creativity, and the Commons. Halifax \& Winnipeg: Fernwood. doi:10.5040/ 9781350219410.ch-003

Hanslick, E., and Payzant, G. (1986). On the Musically Beautiful: A Contribution towards the Revision of the Aesthetics of Music. Indianapolis, Ind: Hackett Pub. Co.

Harding, C. (2016). How the Pop-Drop Became the Sound of 2016. Available at: https://www.billboard.com/articles/events/year-in-music-2016/7625628/popdrop-sound-of-2016-chainsmokers-justin-bieber-switched-on-pop/ (Accessed December 19, 2016).

Hourigan, R., and Edgar, S. (2014). "Phenomenological Research in Music Education," in The Oxford Handbook of Qualitative Research in American Music Education. Editor C. Conway (New York, NY: Oxford University Press), 148-162.

Hurley, S. (1998). Consciousness in Action. Cambridge, Mass: Harvard University Press.

Hurley, S. (2010). Rational Animals? Oxford: Oxford Univ. Press. doi:10.1093/ oxfordhb/9780199235476.003.0038

Husserl, E. (1964). The Idea of Phenomenology. The Hague: Martinus Nijhoff. doi:10.3196/9783465004769

James, R. (2019). The Sonic Episteme - Acoustic Resonance, Neoliberalism, and Biopolitics. Durham \& London: Duke University Press. doi:10.1215/ 9781478007371

Jocson, K. (2018). Youth Media Matters: Participatory Cultures and Literacies in Education. Minneapolis, MN: University of Minnesota Press. doi:10.5749/j. cttlpwt78w

Jorgensen, E. (1997). In Search of Music Education. Urbana: University of Illinois Press.

Kheshti, R. (2015). Modernity's Ear - Listening to Race and Gender in World Music. New York, NY: New York University Press.

Kivy, P. (2002). Introduction to a Philosophy of Music. Oxford: Clarendon Press.

Kramer, L. (2011). Interpreting Music. Berkeley: University of California Press. doi:10.1525/california/9780520267053.001.0001

Krause, B. (1996). Notes from the Wild: The Nature Recording Expeditions of Bernie Krause with Companion CD. Roslyn, NY: Ellipsis Arts.

Krause, B. (2012). The Great Animal Orchestra: Finding the Origins of Music in the World's Wild Place. New York: Little, Brown and Company.

Lewin, D. (1986). Music Theory, Phenomenology, and Modes of Perception. Music Perception: Interdiscip. J. 3 (4), 327-392. doi:10.2307/40285344

Lewis, T. (2020). Walter Benjamin's Antifascist Education-from Riddles to Radio. Albany, NY: SUNY Press.

Lingold, M. C., Mueller, D., and Trettien, W. A. (2018). Digital Sound Studies. Durham, NC: Duke University Press. Available at: http://catalog.hathitrust. org/api/volumes/oclc/1010505898.html.

McClary, S. (1991). Feminine Endings: Music, Gender, and Sexuality. Minneapolis: University of Minnesota Press. 
Mithen, S. (2005). The Singing Neanderthals: The Origins of Music, Language, Mind and Body. London: Weidenfeld \& Nicolson.

Noë, A. (2006). Action in Perception. Cambridge, Mass: MIT. doi:10.1002/ 0470018860.s00170

O'Callaghan, C. (2017). Beyond Vision - Philosophical Essays. London, UK: Oxford University Press.

Odland, B., and Auinger, S. (2009). Reflections on the Sonic Commons. Leonardo Music J. 19, 63-68. doi:10.1162/lmj.2009.19.63

Oliveros, P. (2005). Deep Listening - A Composer's Sound Practice. New York, London, and Shanghai: IUniverse, Inc.

P. Burnard, Y. Trulsson, and J. Söderman (2015). in Bourdieu and the Sociology of Music Education. Farnham Surrey (England: Ashgate Publishing Limited).

Pinch, T. J., and Bijsterveld, K. (2017). The Oxford Handbook of Sound Studies. New York: Oxford University Press.

Pio, F., and Varkøy, Ø. (2015). Philosophy of Music Education Challenged: Heideggerian Inspirations: Music, Education and Personal Development. Dordrecht: Springer. Available at: http://public.ebookcentral.proquest.com/ choice/publicfullrecord.aspx? $\mathrm{p}=1968038$.

Rice, T. (2010). Learning to Listen: Auscultation and the Transmission of Auditory Knowledge. J. R. Anthropological Inst. 16, 41-61. doi:10.1111/j.1467-9655.2010.01609.x

Rice, T. (2016). Sounds inside: Prison, Prisoners and Acoustical Agency. Sound Stud. 2 (1), 6-20. doi:10.1080/20551940.2016.1214455

Rinsema, R. (2017). Listening in Action - Teaching Music in the Digital Age. SEMPRE Studies in the Psychology of Music. London \& New York: Routledge.

Rosa, H. (2020). Resonance - A sociology of our relationship to the world. (James C. Wagner, Tr.). Medford, MA: Polity Press.

Rothenberg, D. (2019). Nightingales in Berlin: Searching for the Perfect Sound. Chicago: University of Chicago Press. doi:10.7208/chicago/9780226467214.001.0001

Rothenberg, D., and Ulvaeus, M. (2001). The Book of Music and Nature: An Anthology of Sounds, Words, Thoughts. Middletown, CT: Wesleyan University Press.
R. Wright (2010). in Sociology and Music Education (London \& New York: Routledge).

Schmidt, P., and Edwards, J. (2022). "Composition, Policy and the Formation of Agency - Pathways in Teacher Education and K-16 Practice," in The Oxford Handbook of Music Composition Pedagogy. Editor M. Kaschub (Oxford University Press).

Siisiäinen, L. (2013). Foucault and the Politics of Hearing. Milton Park, Abingdon, Oxon, Ox: Routledge.

Sloan, N., Harding, C., and Gottlieb, I. (2020). Switched on Pop: How Popular Music Works, and Why it Matters. New York: Oxford University Press. doi:10.1093/ oso/9780190056650.001.0001

Small, C. (1977). Music, Society, Education: An Examination of the Function of Music in Western, Eastern and African Cultures with its Impact on Society and its Use in Education. Hannover \& London: University Press of New England. Sterne, J. (2012). The Sound Studies Reader. New York: Routledge.

Stoever, J. (2016). The Sonic Color Line - Race and the Cultural Politics of Listening. New York, NY: New York University Press. doi:10.2307/j.ctt1bj4s55

Voegelin, S. (2014). Sonic Possible Worlds - Hearing the Continuum of Sound. New York, NY: Bloomsbury.

Conflict of Interest: The authors declare that the research was conducted in the absence of any commercial or financial relationships that could be construed as a potential conflict of interest.

Copyright (C) 2021 Rinsema and Edwards. This is an open-access article distributed under the terms of the Creative Commons Attribution License (CC BY). The use, distribution or reproduction in other forums is permitted, provided the original author(s) and the copyright owner(s) are credited and that the original publication in this journal is cited, in accordance with accepted academic practice. No use, distribution or reproduction is permitted which does not comply with these terms. 